\title{
Chronic spontaneous urticaria
}

\author{
Jane Hsieh MD, Jason K. Lee MD
}

Cite as: CMAJ 2017 January 16;189:E77. doi: 10.1503/cmaj.150951

See also www.cmaj.ca/lookup/doi/10.1503/cmaj.150154

\section{Chronic spontaneous urticaria is defined by the presence of hives daily or almost daily for at least six weeks Patients present with recurrent, pruritic, wheal-and-flare lesions that fade within 24 hours without scarring. ${ }^{1}$ The condition can occur with angioedema in $30 \%-50 \%$ of patients and should be differentiated from acute urticaria (lasting $<6$ weeks) and physically induced urticaria (e.g., by cold tempera- tures or delayed pressure). ${ }^{1}$}

2 The condition primarily affects the working population and may have a substantial impact on quality of life Chronic spontaneous urticaria has a peak incidence between the ages of 20 and 40 years, lasting one to five years in most patients, but longer in severe cases. ${ }^{2}$ The condition affects $0.5 \%-1 \%$ of the general population; ${ }^{2}$ women are affected twice as often as men. ${ }^{3}$ School or job performance and sleep can be substantially affected. ${ }^{2}$

\section{3}

Although the pathophysiology is unknown, autoimmune mechanisms have been proposed

Immunoglobulin $\mathrm{E}$ (IgE) autoantibodies have been implicated in the cause of chronic spontaneous urticaria, and autoimmune conditions, such as thyroid disease and systemic lupus erythematosus, have been found to be associated with the condition. ${ }^{3}$ In contrast to acute urticaria, chronic spontaneous urticaria is not usually caused by IgE-mediated reactions to external allergens (e.g., food). ${ }^{1}$

The diagnosis is based on a thorough history and physical examination

A recent guideline recommends avoiding extensive testing, because most patients will have no identifiable cause. ${ }^{1}$ Initial investigations should be limited to a complete blood count with differential, C-reactive protein and erythrocyte sedimentation rate to exclude underlying malignant disease or an inflammatory condition. ${ }^{1}$

5

First-line treatment is a second-generation $\mathrm{H}_{1}$-antihistamine

Because the condition is self-limiting, the goal of treatment is symptomatic relief. Second-generation $\mathrm{H}_{1}$-antihistamines are preferred over first-generation antihistamines because they are less sedating and have fewer anticholinergic effects. ${ }^{1,4}$ For cases refractory to standard doses of $\mathrm{H}_{1}$-antihistamines (up to $50 \%$ of cases), treatment can be escalated (Appendix 1, available at www.cmaj .ca/lookup/suppl/doi:10.1503/cmaj.150951/-/DC1). Referral to a clinical allergist and immunologist is useful for discussing third-line treatment options. ${ }^{1,2,5}$

\section{References}

1. Zuberbier T, Aberer W, Asero R, et al. The EAACI/GA(2) LEN/EDF/ WAO Guideline for the definition, classification, diagnosis, and management of urticaria: the 2013 revision and update. Allergy 2014;69:868-87.

2. Maurer M, Weller K, Bindslev-Jensen C, et al. Unmet clinical needs in chronic spontaneous urticaria. A GA(2)LEN task force report. Allergy 2011;66:317-30.

3. Confino-Cohen R, Chodick G, Shalev V, et al. Chronic urticaria and autoimmunity: associations found in a large population study. J Allergy Clin Immunol 2012;129:1307-13.

4. Sharma M, Bennett $\mathrm{C}$, Carter B, et al. $\mathrm{H}_{1}$-antihistamines for chronic spontaneous urticaria: an abridged Cochrane Systematic Review. J Am Acad Dermatol 2015;73:710-716.e4.

5. Kaplan A, Ledford D, Ashby M, et al. Omalizumab in patients with symptomatic chronic idiopathic/spontaneous urticaria despite standard combination therapy. J Allergy Clin Immunol 2013;132:101-9.

Competing interests: Jason Lee reports receiving grants and personal fees from Novartis AG Canada and Merck Canada. No other competing interests were declared.

This article has been peer reviewed.

Affiliations: Department of Medicine (Hsieh), Gordon and Leslie Diamond Health Centre, University of British Columbia, Vancouver, BC; Allergy and Clinical Immunology (Lee), University of Toronto, Toronto, Ont.

Correspondence to: Jane Hsieh, hsieh.jane@ gmail.com 